\title{
The Frequency and Clinical Significance of Sister Chromatid Exchange in the Lymphocyte of Gastric Cancer Patient Exposed to Hypoxia
}

\author{
Jae-Ho Lee ${ }^{1,2}$, Ki-Sang Eom ${ }^{3}$, In-Ho Kim ${ }^{4}$, Dae-Kyu Song ${ }^{5}$, In-Jang Choi ${ }^{1} \&$ Dae-Kwang Kim ${ }^{1,2,6}$ \\ ${ }^{1}$ Department of Anatomy, Keimyung University College of Medicine, Daegu, Korea \\ ${ }^{2}$ Institute for Medical Genetics, Keimyung University College of Medicine, Daegu, Korea \\ ${ }^{3}$ Medical Course, Keimyung University College of Medicine, Daegu, Korea \\ ${ }^{4}$ Department of Surgery, Keimyung University College of Medicine, Daegu, Korea \\ ${ }^{5}$ Chronic Disease Research Center, School of Medicine, Keimyung University, Daegu, Republic of Korea \\ ${ }^{6}$ Hanvit Institute for Medical Genetics, Daegu, Korea \\ Correspondence: Dr. Dae-Kwang Kim, Department of Anatomy, Keimyung University School of Medicine, \\ 2800, Dalgubeoldaero, Dalseo-Gu, Daegu, Republic of Korea. Tel: 82-53-580-3832. Fax: 82-53-580-3835. \\ E-mail: dkkimmd@kmu.ac.kr
}

Received: February 28, 2012 Accepted: March 12, 2012 Online Published: May 1, 2012

doi:10.5539/cco.v1n $1 \mathrm{p} 102$

URL: http://dx.doi.org/10.5539/cco.v1n1p102

The authors declare that there are no conflicts of interest

\begin{abstract}
The frequency of sister chromatid exchange (SCE) in patients with gastric cancer is significantly higher than that in normal individuals; however, their characteristics have not been studied. In present study, we analyzed the correlation between the cytogenetic instability of gastric cancer patients' peripheral lymphocytes with or without hypoxia and the characteristics of gastric cancer patients. The primary lymphocyte cultures obtained from blood samples of 40 healthy donors and 69 patients with gastric cancer were examined using SCE. The average of SCE frequency in gastric cancer was $5.91 \pm 2.03$ cell and the SCE phenotype was not associated with gender, tumor grade, Lauren classification, and H.pylori infection. Hypoxia increased the SCE frequency as compared with normoxia, in both the control and gastric cancer lymphocyte cultures $(P<0.001)$. The hypoxic effect in gastric cancer was not associated with gender, tumor grade, Lauren classification, and H.pylori infection. In conclusion, hypoxia did not facilitate an increase of SCE in the lymphocytes of the gastric cancer.
\end{abstract}

Keywords: gastric cancer, hypoxia, sister chromatid exchange

\section{Introduction}

Gastric cancer, as a leading cause of cancer death, is the most common malignancy in Korea (Parkin et al., 1993). Its carcinogenesis was ranged from chronic gastritis to atrophy, intestinal metaplasia, dysplasia, and finally invasive cancer (Leung et al., 2000; Correa \& Shiao, 1994). Because this process is strongly involved with genetic instability, various studies related to genetic instability have been conducted by many authors (Lengauer et al., 1998; Lee et al., 2002; Habano et al., 2000; hamamoto et al., 1997; Zaky et al., 2008; Kobayashi et al., 2000; Jeong et al., 2010). For simplicity, genetic instability can be classified into chromosomal instability (CIN) and microsatellite instability (MSI), which is occurred at the chromosomal and nucleotide levels, respectively. According to these studies, genetic instability affects the clinicopathological features and the prognosis of the cancer.

Hypoxia is a key regulatory factor in many diseases such as certain forms of cancer and cardiovascular diseases (Harris, 2002; Hockel \& Vaupel, 2001). Many attentions have been focused on hypoxia, and especially in tumor as a tumor microenviromental factor (Reynolds et al., 1996; Huang et al., 2007; Papp-Szabo et al., 2005; Bindra \& Glazer, 2005). To elucidate the role of hypoxia, it is extremely helpful to study the effect of hypoxia not only in cancer cell but also in normal cell. Our previous study demonstrated that hypoxia itself increased DNA damage in the lymphocyte of healthy populations by using sister chromatid exchange (SCE) (Lee et al., 2010). 
SCE can detect the cytogenetic damage by genotoxic agents or environmental agents (Carrano et al., 1978; Solomon \& Bobrow, 1975). A significant increased number of SCEs has been previously reported in patients with various cancers, including gastric cancer (Park \& Kim, 1999; Roy et al., 2000; Cortés-Gutiérrez et al., 2000; Aristei et al., 2009). However, there has been no study that has examined the relation between the clinicopathological features of gastric cancer patients and the SCE pattern.

In this study, we analyzed the correlation between the cytogenetic instability and the characteristics of gastric cancer patients. We then examined whether hypoxia can lead to conditions that increase DNA damage of the peripheral lymphocytes of gastric cancer patients.

\section{Materials and Methods}

\subsection{Patients}

The Division of General Surgery at Dongsan Medical Center provided whole heparinized blood samples from 69 patients with gastric cancer. The characteristics of the patients are summarized in Table 1. The patients had no history of chemotherapy, radiotherapy or chronic infection. The regional institutional review board (IRB) approved this study and informed written consent was obtained from all the individuals involved in the study.

Table 1. Characteristics of patients with gastric cancer

\begin{tabular}{lc}
\hline & Gastric cancer $(\mathrm{n}=69)$ \\
\hline Age (mean) & $56.4(34-81)$ \\
Gender & 32 \\
Male & 37 \\
Female & \\
Grade & 36 \\
EGC & 33 \\
AGC & \\
Type & 35 \\
Diffuse & 34 \\
Intestinal & \\
H.pylori & 26 \\
$(+)$ & 43 \\
$(-)$ & \\
\hline
\end{tabular}

EGC, early gastric cancer; AGC, advanced gastric cancer

\subsection{Cell Culture and the Hypoxic Condition}

$1.0 \mathrm{~mL}$ of blood sample was cultured in $9.0 \mathrm{~mL}$ of RPMI 1640 medium with $10 \%$ fetal bovine serum (Hyclone, Utah, USA). The lymphocytes were stimulated by phytohemagglutinin (PHA-M, Gibco, Scotland, UK). Hypoxic cultures were placed at $37{ }^{\circ} \mathrm{C}$ in a humidified atmosphere of $92 \% \mathrm{~N} 2 / 5 \% \mathrm{CO} 2 / 3 \%$ O2 using controlled atmosphere incubator (ASTEC, Fukuoka, Japan). Exposure groups were divided according to exposure time (12 and 24 hours)

\subsection{Sister Chromatid Exchange Assay}

The methods used for the SCE test were as previously described with minor modifications (Lee et al., 2010). The cultured cells were incubated for $72 \mathrm{hr}$ and $10 \mu \mathrm{g} / \mathrm{mL}$ 5-bromodeoxyuridine (BrdU, Sigma, USA) was added after $24 \mathrm{hr} .10 \mu \mathrm{g} / \mathrm{mL}$ colcemid (Gibco, UK) was added for the final $2 \mathrm{hr}$. Cells were harvested by hypotonic treatment $(0.075 \mathrm{M} \mathrm{KCl})$ for $10 \mathrm{~min}$ at $37^{\circ} \mathrm{C}$ and fixation in $3: 1$ methanol and acetic acid. cell suspension was dropped onto slides and the Höechst-Giemsa stain was performed. The SCE of the lymphocytes was microscopically examined and counted by using a Zeiss Axioskop and the Cytovision Computer-Assisted Karyotyping System (Applied Imaging, Santa Clara, CA, USA). 30 well-spread second division metaphases were analyzed for each donor. The results were calculated as the mean number of SCEs (SCEs/cell). 


\subsection{Statistical Analysis}

The statistical analysis of the experimental values was performed by Student's $t$-test.

\section{Results}

\subsection{SCE Frequency in Gastric Cancer}

The SCE frequency was examined in 69 patients with gastric cancer and this is summarized in Table 2. The average (mean $\pm \mathrm{SD}$ ) SCE level in gastric cancer was $5.91 \pm 2.03 /$ cell. The SCE phenotype was not associated with gender, the tumor grade, Lauren's classification, and H.pylori infection (Table 3).

Table 2. The average of SCE frequency (Mean SCEs \pm SD) in gastric cancer according to exposed to hypoxia

\begin{tabular}{lccc}
\hline & Normoxia & Hypoxia $12 \mathrm{~h}$ & Hypoxia 24h \\
\hline Control & $4.30 \pm 1.87 /$ cell & $5.88 \pm 1.98 /$ cell* $^{*}$ & $6.29 \pm 2.07 /$ cell* $^{*}$ \\
Gastric cancer & $5.91 \pm 2.09 /$ cell & $6.88 \pm 1.71 /$ cell** $^{*}$ & $7.11 \pm 1.74 /$ cell** $^{*}$ \\
\hline
\end{tabular}

* Significant difference compared to normoxia in Control $\mathrm{P}<0.001$ (Student $\mathrm{t}$-test)

** Significant difference compared to normoxia in Gastric cancer $\mathrm{P}<0.001$ (Student $\mathrm{t}$-test).

Table 3. Clinicopathologic characteristics of SCE frequency (Mean SCEs \pm SD) in gastric cancer and their response to hypoxia

\begin{tabular}{|c|c|c|c|}
\hline & Normoxia & Hypoxia $12 \mathrm{~h}$ & Hypoxia $24 \mathrm{~h}$ \\
\hline \multicolumn{4}{|l|}{ Gender } \\
\hline Male & $5.96 \pm 1.43 /$ cell & $6.99 \pm 1.75 /$ cell $*$ & $7.22 \pm 1.69 / \mathrm{cell}{ }^{*}$ \\
\hline Female & $5.84 \pm 1.77 /$ cell & $6.76 \pm 1.85 /$ cell $*$ & $6.99 \pm 1.41 /$ cell $^{*}$ \\
\hline$P$ & 0.09 & 0.75 & 0.79 \\
\hline \multicolumn{4}{|l|}{ Grade } \\
\hline EGC & $6.04 \pm 1.35 /$ cell & $6.91 \pm 1.14 /$ cell $*$ & $7.09 \pm 1.52 /$ cell $*$ \\
\hline AGC & $5.76 \pm 1.91 /$ cell & $6.85 \pm 1.44 /$ cell $*$ & $7.14 \pm 1.65 /$ cell $*$ \\
\hline$P$ & 0.50 & 0.21 & 0.24 \\
\hline \multicolumn{4}{|l|}{ Type } \\
\hline Diffuse & $5.87 \pm 1.36 /$ cell & $6.77 \pm 1.37 /$ cell $*$ & $7.09 \pm 1.17 /$ cell $*$ \\
\hline Intestinal & $5.94 \pm 1.66 /$ cell & $7.01 \pm 1.24 /$ cell $*$ & $7.15 \pm 1.34 /$ cell$^{*}$ \\
\hline$P$ & 0.70 & 0.27 & 0.33 \\
\hline \multicolumn{4}{|l|}{ H.pylori } \\
\hline$(+)$ & $5.93 \pm 1.48 /$ cell & $6.97 \pm 1.42 /$ cell $*$ & $7.19 \pm 1.92 /$ cell $^{*}$ \\
\hline$(-)$ & $5.87 \pm 1.52 /$ cell & $6.74 \pm 1.34 /$ cell $*$ & $6.99 \pm 1.28 /$ cell* \\
\hline$P$ & 0.69 & 0.19 & 0.77 \\
\hline
\end{tabular}

EGC, early gastric cancer; AGC, advanced gastric cancer

* Significant difference compared to normoxia $P<0.001$ (Student t-test)

\subsection{Effect of Hypoxia on the SCE in Gastric Cancer Patients}

Two different exposure periods (12 and $24 \mathrm{hr}$ ) were evaluated to determine the genotoxic and cytotoxic effects of hypoxia on the peripheral lymphocytes of the gastric cancer patients in vitro. The mean SCE frequencies of the control group and the two exposure groups with 69 subjects are presented in Table 2. Hypoxia significantly increased the SCE frequency at both exposure periods compared with the normoxia in both the control and gastric cancer groups $(P<0.001)$. The average (mean \pm SD) SCE level under hypoxia for 12 and $24 \mathrm{hr}$ was 6.88 $\pm 1.71 /$ cell and $7.11 \pm 1.74 /$ cell, respectively. However, these frequencies showed no statistical difference. The 
SCE response to hypoxia in the gastric cancer was not associated with gender, the tumor grade, Lauren's classification, and H.pylori infection (Table 3).

\section{Discussion}

This study investigated the clinicopathologic implications of sister chromatid exchange (SCE) in gastric cancer and the responses to hypoxia. A similar rate of increase in the SCE frequency was found between the control and gastric cancer groups. However, these results were not associated with gender, the tumor grade, Lauren's classification, and H.pylori infection.

SCE has generally been investigated in various toxicological studies, yet the recent SCE studies have focused on various cancers. In ovarian cancer, the SCE frequency was higher than that in control, and its frequency was correlated not with the stages of the cancer, but with the CA 125 level (Baltaci et al., 2002). Many authors have showed increased SCE in cervical cancer although some results had no statistical value because of the small sample size (Cortés-Gutiérrez et al., 2000; Murty et al., 1986; Lukovic and Milassin, 1992; Dhillon et al., 1996; Yokota et al., 1989). Breast cancer patients also showed an increased frequency of SCE in a couple of previous studies, and this increased SCE had clinical and genetic significances (Roy et al., 2000; Aristei et al., 2009). Increased SCE was also found in gastric cancer and an H.pylori dependent increase has also suggested (Park and Kim, 1999; Karaman et al., 2008). Base on previous results, we investigated the SCE frequency in 69 gastric cancer patients. We confirmed there was an increased frequency of SCE in gastric cancer and this in agreement with the previously reported results (Park \& Kim, 1999; Karaman et al., 2008).

Various stimulants and chemicals have been introduced as SCE inducers, including hypoxia (Lee et al., 2010; Carrano et al., 1978; Solomon \& Bobrow, 1975). Considering the importance of hypoxia in cancer, we examined the cytogenetic effect of hypoxia in gastric cancer. Based on our previous results (Lee et al., 2010), the lymphocytes from gastric cancer patients were exposed to hypoxia for 12 and 24 hours, respectively. In the gastric cancer, the increased rate of SCE by hypoxia was similar to that in healthy people (Table 2). The two exposure groups showed no statistical difference, indicating no significance of the exposure time of hypoxia. This result suggested that hypoxia does not facilitate increased SCE in gastric cancer. In our preliminary study $(n=36)$, the SCE frequency by hypoxia was significantly different according to the tumor grade (data not shown). To precisely investigate the genetic characteristics of gastric cancer, 33 cases were additionally examined. However, the SCE frequencies in the early and advanced gastric cancers were not significantly different and this result suggested that cytogenetic status in the early and advanced gastric cancer was similar.

The other clinical characteristics, including gender, the Lauren classification and H.pylori infection, were not related to the SCE frequency in both the normoxic and hypoxic statuses. The relation between gastric cancer and the clinical characteristics, except H.pylori infection, has not been studied using SCE. Karaman et al. (2008) described that gastric cancer and patients with H.pylori infection $(9.20 \pm 0.94 /$ cell) had a higher SCE frequency than those without H.pylori $(7.41 \pm 1.36 /$ cell). In gastritis, H.pylori eradication therapy $(5.84 \pm 1.52 /$ cell $)$ decreased the SCE frequency compared to that of the presence of H.pylori infection ( $8.94 \pm 2.01 /$ cell) (Gulten et al., 2002). In our present study, our results showed no association between the SCE frequency and not only gender, the tumor grade and Lauren's classification, but also H.pylori infection in gastric cancer. There was no SCE difference between early and advanced gastric cancers, indicating their similar cytogenetic status. This result suggested that SCE may be early event in gastric carcinogenesis. To prove the role of H.pylori infection in gastric carcinogenesis, further prospective studies on large samples with and without H.pylori infection are necessary.

In conclusion, we confirmed the cytogenetic characteristics in gastric cancer using the SCE method. Hypoxia increased the SCE frequency in the lymphocytes of the gastric cancer patients, yet it may not be an accelerating factor of cytogenetic instability. Considering the critical role of cytogenetic instability in gastric carcinogenesis, the SCE pattern should be investigated in all the multi-step processes of gastric cancer.

\section{Author contributions}

Kim DK was responsible for the review of the literature and initial preparation of the paper. Lee JH and Eom KS analyzed and wrote the paper. Kim IH prepared the samples and their information. Song DK and Choi IJ drafted the article and revised it. 


\section{References}

Aristei, C., Stracci, F., Guerrieri, P., Anselmo, P., Armellini, R., Rulli, A., Barberini, F., Latini, P., \& Menghini, A. R. (2009). Frequency of sister chromatid exchanges and micronuclei monitored over time in patients with early-stage breast cancer: results of an observational study. Cancer Genet Cytogenet, 192(1), 24-29. http://dx.doi.org/10.1016/j.cancergencyto.2009.02.019

Baltaci, V., Kayikçioğlu, F., Alpas, I., Zeyneloğlu, H., \& Haberal, A. (2002). Sister chromatid exchange rate and alkaline comet assay scores in patients with ovarian cancer. Gynecol Oncol, 84(1), 62-66. http://dx.doi.org/10.1006/gyno.2001.6450

Bindra, R. S., \& Glazer, P. M. (2005). Genetic instability and the tumor microenvironment: towards the concept of microenvironment induced mutagenesis. Mutat Res, 569(1-2), 75-85. http://dx.doi.org/10.1016/j.mrfmm m.2004.03.013

Carrano, A. V., Thompson, L. H., Lindl, P. A., \& Minkler, J. L. (1978). Sister chromatid exchanges as an indicator of mutagenesis. Nature, 271(5645), 551-553.

Correa, P., \& Shiao, Y. H. (1994). Phenotypic and genotypic events in gastric carcinogenesis. Cancer Res, 54(7), 1941-1943. http://cancerres.aacrjournals.org/content/54/7_Supplement/1941s

Cortés-Gutiérrez, E. I., Cerda-Flores, R. M., \& Leal-Garza, C. H. (2000). Sister chromatid exchanges in peripheral lymphocytes from women with carcinoma of the uterine cervix. Cancer Genet Cytogenet, 122(2), 121-123. http://dx.doi.org/10.1016/S0165-4608(00)00286-7

Dhillon, V. S., Kler, R. S., \& Dhillon, I. K. (1996). Chromosome instability and sister chromatid exchange (SCE) studies in patients with carcinoma of cervix uteri. Cancer Genet Cytogenet, 86(1), 54-57. http://dx.doi.org/10.1016/0165-4608(95)00168-9

Gulten, T., Tokyay, N., Demiray, M., Gulten, M., Ercan, I., Evke, E., Sardas, S., \& Karakaya, A. E. (2002). The role of triple therapy, age, gender and smoking on the genotoxic effects of Helicobacter pylori infection. $J$ Int Med Res, 30(4), 380-385. http://www.ingentaconnect.com/content/field/jimr/2002/00000030/00000004/ art00003? token $=004912959 \mathrm{~d} 6720297 \mathrm{~d} 7634447 \mathrm{~b} 3 \mathrm{a} 4 \mathrm{a} 752438422 \mathrm{~d} 3 \mathrm{~b} 2 \mathrm{~b} 6 \mathrm{~d} 3 \mathrm{f} 6 \mathrm{a} 4 \mathrm{~b} 6 \mathrm{e} 4 \mathrm{e} 395 \mathrm{e} 4 \mathrm{e} 6 \mathrm{~b} 6331 \mathrm{c} 047 \mathrm{~b}$

Habano, W. Sugai, T. Nakamura, S.I. Uesugi, N. Yoshida, T. Sasou, S. (2000). Microsatellite instability and mutation of mitochondrial and nuclear DNA in gastric carcinoma. Gastroenterology, 118(5). 835-841.

Hamamoto, T., Yokozaki, H., Semba, S., Yasui, W., Yunotani, S., Miyazaki, K., \& Tahara, E. (1997). Altered microsatellites in incomplete-type intestinal metaplasia adjacent to primary gastric cancers. J Clin Pathol, 50(10), 841-846. http://www.ncbi.nlm.nih.gov/pmc/articles/PMC500266/?tool=pubmed

Harris, A. L. (2002). Hypoxia-a key regulatory factor in tumour growth. Nat Rev Cancer, 2(1), 38-47. http://dx.doi.org/10.1038/nrc704

Hockel, M., \& Vaupel, P. (2001). Tumor hypoxia: definitions and current clinical, biologic, and molecular aspects. J Natl Cancer Inst, 93(4), 266-276. http://dx.doi.org/ 10.1093/jnci/93.4.266

Huang, L. E., Bindra, R. S., Glazer, P. M., \& Harris, A. L. (2007). Hypoxia-induced genetic instabilityda calculated mechanism underlying tumor progression. J Mol Med, 85(2), 139-148. http://dx.doi.org/10.1007 /s00109-006-0133-6

Jeong, C. W., Lee, J. H., Sohn, S. S., Ryu, S. W., \& Kim, D. K. (2010). Mitochondrial microsatellite instability in gastric cancer and gastric epithelial dysplasia as a precancerous lesion. Cancer Epidemiol, 34(3), 323-327. http://dx.doi.org/10.1016/j.canep.2010.03.015

Karaman, A., Binici, D. N., Kabalar, M. E., Dursun, H., \& Kurt, A. (2008). Alteration of sister chromatid exchange frequencies in gastric cancer and chronic atrophic gastritis patients with and without H. pylori infection. World J Gastroenterol, 14(16), 2534-2539. http://dx.doi.org/10.3748/wjg.14.2534

Kobayashi, K., Okamoto, T., Takayama, S., Akiyama, M., Ohno, T., \& Yamada, H. (2000). Genetic instability in intestinal metaplasia is a frequent event leading to well-differentiated early adenocarcinoma of the stomach. Er J Cancer, 36(9), 1113-1119. http://dx.doi.org/10.1016/S0959-8049(00)00066-6

Lee, H. S., Choi, S. I., Lee, H. K., Kim, H. S., Yang, H. K., Kang, G. H., ... Kim, W. H. (2002). Distinct clinical features and outcomes of gastric cancers with microsatellite instability. Mod Pathol, 15(6), 632-640. http://www.nature.com/modpathol/journal/v15/n6/full/3880578a.html 
Lee, J. H., Choi, I. J., Song, D. K., \& Kim, D. K. (2010). Genetic instability in the human lymphocyte exposed to hypoxia. Cancer Genet Cytogenet, 196(1), 83-88. http://dx.doi.org/10.1016/j.cancergencyto.2009.09.002

Lengauer, C., Kinzler, K. W., \& Vogelstein, B. (1998). Genetic instabilities in human cancers. Nature, 396(6712), 643-649. http://dx.doi.org/10.1038/25292

Leung, W. K., Kim, J. J., Kim, J. G., Graham, D. Y., \& Sepulveda, A. R. (2000). Microsatellite instability in gastric intestinal metaplasia in patients with and without gastric cancer. Am J Pathol, 156(2), 537-543. http://dx.doi.org/10.1016/S0002-9440(10)64758-X

Lukovic, L., \& Milassin, J. (1992). Sister chromatid exchanges in patients with carcinoma in situ of cervix uteri. Cancer Genet Cytogenet, 59(1), 84-85.

Murty, V. V., Mitra, A. B., Luthra, U. K., \& Singh, I. P. (1986). Sister chromatid exchanges in patients with precancerous and cancerous lesions of cervix uteri. Hum Genet, 72(1), 37-42.

Papp-Szabo, E., Josephy, P. D., \& Coomber, B. L. (2005). Microenvironmental influences on mutagenesis in mammary epithelial cells. Int J Cancer, 116(5), 679-685. http://dx.doi.org/10.1002/ijc.21088

Park, C. S., \& Kim, D. K. (1999). Sister chromatid exchange frequencies in stomach cancer patients. Korean $J$ Anat, 32(5), 615-617.

Parkin, D. M., Pisani, P., \& Ferlay, J. (1993). Estimates of the worldwide incidence frequency of eighteen major cancers in 1985. Int J Cancer, 3(54), 594-606.

Reynolds, T. Y., Rockwell, S., \& Glazer, P. M. (1996). Genetic instability induced by the tumor microenvironment. Cancer Res., 56(24), 5754-5757. http://cancerres.aacrjournals.org/content/56/24/5754.long

Roy, S. K., Trivedi, A. H., Bakshi, S. R., Patel, R. K., Shukla, P. H., Patel, S. J., .. Shah, P. M. (2000). Spontaneous chromosomal instability in breast cancer families. Cancer Genet Cytogenet, 118(1), 52-56. http://dx.doi.org/10.1016/S0165-4608(99)00191-0

Solomon, E., \& Bobrow, M. (1975). Sister chromatid exchanges, A sensitive assay of agents damaging human chromosomes. Mutation Res, 30(2). 273-278. http://dx.doi.org/10.1016/S0027-5107(75)80013-3

Yokota, K., Ueda, K., Ohama, K., \& Fujiwara, A. (1989). Increased spontaneous and mitomicin C-induced sister chromatid exchanges in patients with cancer of the cervix uteri, with special reference to stage of cancer. Cancer Genet Cytogenet. 43(1), 79-97. http://dx.doi.org/10.1016/0165-4608(89)90130-1

Zaky, A. H., Watari, J., Tanabe, H., Sato, R., Moriichi, K., Tanaka, A., ... Kohgo, Y. (2008). Clinicopathologic implications of genetic instability in intestinal-type gastric cancer and intestinal metaplasia as a precancerous lesion: proof of field cancerization in the stomach. Am J Clin Pathol, 129(4), 613-621. http://dx.doi.org/10.1309/DFLELPGPNV5LK6B1 